\title{
MULHERES NO MERCADO DE TRABALHO: ANÁLISE DAS DIFICULDADES DE GÊNERO ENFRENTADAS PELAS MULHERES DO SÉCULO XXI
}

\author{
Felipe Balestrin Seggiaro \\ felipebseggiaro@gmail.com \\ Centro Universitário Metodista - IPA - RS / Brasil
}

\section{RESUMO}

No Brasil, a população feminina é maioria, e há séculos vem lutando pela equiparação de direitos, incluindo-se ai os do mundo do trabalho. A igualdade é fundamental para o desenvolvimento e progresso das organizações e da sociedade como um todo. A partir deste quadro, este artigo se propôs a verificar os desafios enfrentados por um grupo de mulheres, das diferentes regiões demográficas do Brasil e três gestoras, no mercado de trabalho, através de uma pesquisa quantitativa e qualitativa. Se estabeleceu identificar o perfil das pesquisadas; verificar a percepção destas mulheres sobre questões como a discriminação de gênero, assédio, padrões de beleza e diferença salarial no ambiente de trabalho; e averiguar junto às pesquisadas se a maternidade influencia na disputa por vagas ou cargos no ambiente de trabalho.Por meio da análise destas informações coletadas junto das entrevistadas foi possível concluir que o universo de mulheres da pesquisa sentem que há uma grande diferença entre o tratamento dispensado aos dois gêneros no mundo do trabalho e que os diversos direitos assegurados por lei, não impedem a discriminação de gênero.

PALAVRAS-CHAVE: Gênero; Gestão da diversidade; Mulher no mercado trabalho. 


\section{WOMEN IN THE LABOR MARKET: ANALYSIS OF GENDER DIFFICULTIES FACED BY WOMEN IN THE 21ST CENTURY}

\section{ABSTRACT}

In Brazil, the female population is the majority, and for centuries it has been fighting for equal rights, including those in the world of work. Equality is fundamental to the development and progress of the organization and of society as a whole. Based on this framework, this article aims to verify the challenges faced by a group of women from the different demographic regions of Brazil and three managers in the labor market through a quantitative and qualitative research. It was established to identify the profile of those surveyed; To verify the perception of these women on issues such as gender discrimination, harassment, beauty standards and wage differences in the workplace; And to inquire with the respondents if maternity affects the dispute for positions or positions in the work environment. Through the analysis of this information collected from the interviewees, it was possible to conclude that the universe of women in the research feel that there is a great difference between the treatment of both genders in the world of work and that the various rights guaranteed by law do not prevent discrimination of gender.

KEYWORDS: Genre; Diversity management; Woman at work market.

\section{INTRODUÇÃO}

Na sociedade contemporânea as mulheres estão à frente de muitas organizações, todavia ainda existem resquícios dos séculos passados, limitando o mundo feminino em pleno século XXI. No mercado de trabalho as mulheres ainda recebem sistematicamente menos que os homens, e enfrentam diariamente problemas, como a discriminação de gênero, o assédio, a imposição de padrões de beleza e o machismo, ainda presentes nas empresas.

Num passado não muito remoto, as mulheres viviam em casa, somente para um universo de trabalhos domésticos, doutrinadas desde cedo para a submissão aos homens e pouco sabiam sobre sua sexualidade e seu corpo. Essa cultura arcaica 
prevalece nos dias atuais, pois a sociedade ainda tenta esculpir o que é a figura feminina e masculina. Desde sempre os pais, as escolas e a sociedade de uma forma geral, educam as meninas para se comportar de uma maneira e os meninos, de outra. Este quadro não é diferente nas organizações, já que o ambiente de trabalho nas empresas nos séculos transcorridos era somente para homens, e as mulheres eram desencorajadas e até mesmo impedidas de ingressar no mercado de trabalho.

De acordo com Neves (2009), o mercado pode ser impiedoso com as mulheres, resultado de vários séculos opressão, e uma formação acadêmica não muda essas circunstâncias, já que mesmo depois de formadas as mulheres ganham menos e têm menos autoridade que seus colegas homens, até aquelas que se destacam por suas notas na academia ou competência profissional. Como destaca o autor, apesar deste contexto, cada vez mais a presença da mulher é significativa no mercado de trabalho, também cresce o número de mulheres chefe de família e o percentual de meninas é maior que o de meninos nas escolas, esses fatores são importantes para diminuir a desigualdade de gênero que ainda persiste no país.

Conforme Beauvoir (1970), as mulheres que batalham pelo sucesso e sua autonomia, dispõe de menos oportunidades que seus colegas masculinos, pelo fato de que recém chegarem ao mundo dos homens. Há homens que rejeitam se submeter ao comando feminino, esses homens têm mais segurança em ordens de outros homens, por isso o sexo masculino ainda preenche as melhores vagas e os postos mais relevantes, mostrando que no mundo do trabalho, ainda existem duas raças: a masculina e a feminina.

Frente ao exposto, este estudo buscou verificar os desafios enfrentados por um grupo de mulheres, das diferentes regiões demográficas do Brasil e três gestoras, no mercado de trabalho. Para alcançar plenamente este objetivo, foram traçados os per- 
fis das pesquisadas; se identificou percepção das pesquisadas sobre a discriminação de gênero, assédio, padrões de beleza e diferença salarial no ambiente de trabalho; e se averiguou junto às pesquisadas se a maternidade influencia na disputa por vagas ou cargos no ambiente de trabalho.

\section{REFERENCIAL TEÓRICO}

De acordo com Stearns (2010) nas corporações patriarcais foi conceituado que os homens eram seres superiores às mulheres, sendo que estes possuíam mais direitos legais que as elas. $\mathrm{O}$ código de Hamurabi, considerado a jurisprudência mais antiga do mundo, determinava que uma mulher que não era uma boa dona de casa, que levava um a vida ociosa, que diminuísse ou descuidasse do marido deveria ser arremessada à água. A desigualdade se tornou mais forte com o passar dos anos, a lei judaica posterior ao código de Hamurabi era mais rigorosa com as mulheres nas abordagens da sexualidade e do papel público. Nessa mesma época surgiu a prática do uso do véu no oriente médio, quando as mulheres estivessem em público, mostrando a sua inferioridade e que eram propriedade de seus pais e maridos.

De acordo com Vianna (1993), graças aos pensamentos do cristianismo e aos dos homens na Idade Moderna, a mulheres foram mantidas nesse sistema de cárcere privado, por obra dos costumes que vinham se arrastando junto aos séculos e, através do casamento, as mulheres eram enclausuradas no lar. As mudanças nesta realidade foram lentas, como destaca Lopes (2015), no final dos anos dez, se iniciou o debate sobre o projeto de código do trabalho no Brasil, foi discutida a possibilidade da mulher casada poder trabalhar sem a prévia aprovação do cônjuge, causando uma grande objeção e contestação na época, não sendo aprovada esta proposta pelos parlamentares. Neste contexto, Fonseca (2004) destaca que 
as mulheres das classes menos favorecidas economicamente, sobreviviam na dualidade da moralidade oficial, totalmente dissociada da efetiva realidade, com dois parâmetros diametralmente opostos, decorrentes do salário ínfimo do marido, insuficiente para atender as necessidades básicas. Entretanto a dona de casa que tentava mudar essa realidade de miséria, assumindo seu próprio trabalho, ariscava ser chamada pejorativamente de mulher pública.

Coelho (2002) afirma que as mulheres viveram a sua história efetivamente asfixiadas sobre o absolutismo dos homens nas circunstâncias condescendentes em que se acreditava que fazia parte da moral e os bons costumes, desde modo restringindo a liberdade das mulheres e as excluindo dos trabalhos e do sistema de ensino superior. Deste modo, conforme Bello (2012), durante séculos as meninas foram consideradas propriedades dos homens e só a partir do século XIX, depois de movimentos feministas, a mulher se tornou visível e não mais passiva em relação aos homens, sendo integrada realmente na sociedade. O autor ainda completa, expondo que "historicamente, poucas mulheres tiveram papel que merecesse alguma relevância. A história, no que diz respeito às mulheres, tem sido profundamente evasiva." (BELLO, 2012, p. 20).

Segundo Vianna (1993), com a chegada da tecnologia, o pensamento que as mulheres são o sexo mais fraco se revogou, uma vez que na atualidade para movimentar máquinas de grande porte basta apertar um botão, dessa forma cada vez mais se destacam homens e mulheres que usam o entendimento e a inteligência do que propriamente a força, acabando com a rigidez desse pensamento remoto. Nesta realidade, Heath (2013) expõe que o ingresso da mulher no mercado de trabalho melhorou a vida delas, pois existem indícios e argumentos teóricos que o acesso da mulher ao mercado de trabalho diminui o casamento precoce e a gravidez, e aumenta a influência 
da mulher dentro do lar e as oportunidades dos filhos, já que aumenta a renda e as mães podem buscar escolas e planos de saúde melhores para a família.

Besamusca et al. (2015) propõem que a integração das mulheres no mercado de trabalho ajuda no crescimento do bem-estar de famílias inteiras, refletindo no crescimento econômico e reduzindo a pobreza, ou seja, é importante na definição do desenvolvimento econômico e humano do país. Em razão disso, surgiram políticas dirigidas para a melhoria da posição das mulheres nas sociedades.

Na América do Norte, entre os anos 1950 até 2000, o índice de mulheres no mercado passou de $34 \%$ para $60 \%$. No Brasil essa aceleração foi mais lenta, pois nos anos 70 as mulheres representavam só $18 \%$ do mercado de trabalho. Já em 2002, segundo o IBGE, os números alcançavam 50\% da presença feminina no mercado de trabalho (MADALOZZO; MARTINS; SHIRATORI, 2010). Apesar dos progressos, Besamusca et al. (2015) afirmam que ainda não podem ser equiparados em números os empregos oferecidos para homens e mulheres, e esta oferta pode ser considerada limitada a alguns setores e profissões com remunerações menores.

De acordo com Salahodjaev e Azam (2015), alguns especialistas propõem que países com o regime democrático apresentam um maior equilíbrio de gêneros em comparação a países com regimes mais autoritários, já que nos primeiros as mulheres representarem grande parte eleitorado. Neste contexto, Ng e Wyrick (2011) expõem que apesar da mão de obra se tornar progressivamente mais diversificada, em medidas de sexo e raça, as empresas ainda não obtiveram êxito na completa integração das mulheres e minorias raciais no mercado de trabalho. Esta afirmativa vem ao encontro de Fleury (2000) que expõe que a compreensão da diversidade está relacionada ao respeito à personalidade dos empregados. Administrar a 
diversidade inclui progressos às aptidões necessárias para o desenvolvimento e ao êxito do negócio.

Em harmonia com Ng e Wyrick (2011), diversos pesquisadores têm mostrado que cada vez mais as organizações se compromem em aumentar a diversidade na sua força de trabalho, atraindo uma maior sustentação de clientes e aumentando os lucros da empresa. Mesmo que o eixo principal da maioria dos programas neste sentido tenham foco na inclusão das mulheres e da raça negra, os esforços mais contemporâneos da gestão da diversidade têm por objetivo incluir também outras pautas, tais como: deficiência, orientação sexual, religião, classe social e diferentes nacionalidades.

A discussão sobre a diversidade no ambiente de trabalho não é nova, no século passado Thomas e Ely (1996) já apontavam vantagens na diversidade, assegurando que os gestores necessitam entender que uma força de trabalho diversificada vai abarcar diferentes pontos de vista e abordagens para o trabalho, trazendo consequentemente variedade de visões, opiniões e percepções para organização. De acordo com $\mathrm{Ng}$ e Wyrick (2011) os grandes executivos e líderes compreendem que é necessário mudar e sabem a importância e a influência da gestão da diversidade nos resultados das organizações. A gestão da diversidade, frequentemente requer esforços de longo prazo, pois os benefícios da agregação da diversidade não são imediatamente percebidos. Sobre estes benefícios, Thomas e Ely (1996) afirmam que as organizações necessitam ter discussões claras e transparentes de como as diferenças podem ser utilizadas como geradoras de desenvolvimento e eficácia individual e organizacional.

Em conformidade com o exposto, Meric, Er e Gorun (2015) expõem que o conceito da diversidade vem sendo estudado pelas ciências administrativas aproximadamente há 25 anos, onde as universidades que promovem a diversidade nos seus 
ambientes organizacionais, também promovem e incentivam o respeito recíproco, aceitando e compreendendo as diferenças. Ainda segundo Meric, Er e Gorun (2015) no mundo contemporâneo, a diversidade nas organizações é muito mais ampla dos que nos séculos transcorridos, pois o número de funcionários de uma mesma empresa com diferentes origens e valores é cada vez maior. As organizações que obtêm e que motivam uma força de trabalho diversificada são capazes de aumentar a criatividade e inovação organizacional, desde modo alcançando um maior número de clientes.

\section{METODOLOGIA}

Esse estudo se caracterizou como uma pesquisa mista, que de acordo com Creswell (2010) são as pesquisas que apresentam uma combinação de abordagens quantitativas e qualitativas, destacando que este é um método relativamente novo nas ciências sociais e humanas.

Para a etapa de pesquisa qualitativa foram entrevistadas três mulheres com cargos de chefia em empresas. Estas mulheres foram escolhidas a partir do sucesso que alcançaram em suas carreiras, caracterizando uma amostragem intencional, elas serão os sujeitos da pesquisa. Na visão de Klein et al. (2015, p. 52) define-se como sujeitos da pesquisa os participantes da mesma, e que estes predominam em pesquisas qualitativas, sendo "aqueles que estão mais próximos ou envolvidos com o fenômeno que está sendo pesquisado". A escolha destas executivas se deu de forma intencional, sendo que, de acordo com Gil (2002), este tipo de amostragem faz com que a pesquisa fique mais completa e favorável em termos qualitativos, já que seleciona um público alvo, possibilitando identificar as atitudes desse grupo, trazendo informações ricas para a pesquisa.Com o objetivo de manter o anonimato das pesquisadas, em função do caráter pessoal das questões abor- 
dadas, as gestoras serão doravante identificadas como Gestora A, com 23 anos de experiência; e Gestoras B e C, ambas com 22 anos de experiência no mercado de trabalho.

$\mathrm{Na}$ etapa quantitativa foram pesquisadas mulheres acessadas através de questionário do GoogleDocs, pacote de aplicativos do Google, onde se buscou totalizar pelo menos 100 mulheres em cada região do país, já que a pesquisa pretendeu fazer um amplo retrato das questões de gênero no Brasil. Assim as pesquisas abrangeram as cinco regiões demográficas brasileiras: Norte, Nordeste, Centro-Oeste, Sudeste e Sul, somando ao todo 841 respondentes, com 103 respondentes da Região Norte; 114 da Região Nordeste; 107 da Região Centro-Oeste, 139 provenientes da Região Sudeste; e 379 participantes da Região Sul.O link ficou ativo entre o dia 05 de agosto a 05 de outubro de 2016.

Uma vez organizados os resultados da pesquisa quantitativa e da qualitativa buscou-se estabelecer vínculos entre os dados provenientes dos dois grupos pesquisados e com os conhecimentos teóricos, em uma análise interpretativa dos dados. Como destacam Marconi e Lakatos (2010), neste tipo de análise é realizada a interpretação da exposição do verdadeiro significado do material apresentado, levando em consideração os objetivos propostos e ao tema. Além de esclarecer o significado do material, faz ilações amplas dos dados discutidos.

Como etapa final, os dados obtidos foram confrontados com a bibliografia abordada neste artigo, além de levar em consideração o objetivo proposto nesta pesquisa.

\section{RESULTADOS DA PESQUISA}

Visando identificar o perfil das gestoras, partindo da pesquisa qualitativa, dirigida a três gestoras, o autor elaborou quatro perguntas se iniciando com a formação de cada uma 
delas. Como estabelecido na metodologia, as entrevistadas foram identificadas como: Gestora A, Gestora B e Gestora C.

O Quadro 1 sumariza o perfil das entrevistadas, onde se pode perceber que há semelhanças entre elas, pois todas buscaram formação em suas áreas de atuação, corroborando a literatura, pois os dados do IPEA (2011) apontam que a taxa de escolarização líquida no ensino superior entre as mulheres é $1 \%$ superior a dos homens, sendo esta uma necessidade do mercado de trabalho, que exige, para o mesmo cargo, uma maior qualificação das mulheres, conforme destaca Bassanezi (2004).

Quadro 1 - Comparação entre os perfis das gestoras pesquisadas

\begin{tabular}{|l|c|c|c|}
\cline { 2 - 4 } \multicolumn{1}{c|}{} & Gestora A & Gestora B & Gestora C \\
\hline $\begin{array}{l}\text { Cargo que } \\
\text { ocupa }\end{array}$ & $\begin{array}{c}\text { Coordenadora de } \\
\text { uma curso de IES } \\
\text { e representante de } \\
\text { entidade de classe } \\
\text { federal }\end{array}$ & Reitora de IES & $\begin{array}{c}\text { Gestora } \\
\text { administrativa de } \\
\text { empresa familiar }\end{array}$ \\
\hline Formação & $\begin{array}{c}\text { Mestrado e } \\
\text { Doutorado }\end{array}$ & $\begin{array}{c}\text { Mestrado e } \\
\text { Doutorado }\end{array}$ & $\begin{array}{c}\text { Superior em } \\
\text { andamento } \\
\text { (incompleto) }\end{array}$ \\
\hline Idade & 43 & 45 & 39 \\
\hline $\begin{array}{l}\text { Idade em } \\
\text { que iniciou } \\
\text { a atividade } \\
\text { remunerada }\end{array}$ & 19 & 23 & 17 \\
\hline Filhos & 2 & 2 & 1 \\
\hline
\end{tabular}

Fonte: o autor, 2016

Outra semelhança entre as Gestoras A, B e C que o Quadro 1 aponta é a presença de filhos, sugerindo que estas três mulheres compatibilizaram a vida familiar e a vida profissional que, em geral, na realidade brasileira, significa uma jornada dupla de trabalho (IPEA, 2011)

Outra semelhança entre as Gestoras A, B e C que o Quadro 1 aponta é a presença de filhos, sugerindo que estas três 
mulheres compatibilizaram a vida familiar e a vida profissional que, em geral, na realidade brasileira, significa uma jornada dupla de trabalho (IPEA, 2011)

Com relação a pesquisa quantitativa, para traçar o perfil das 841 respondentes, o pesquisador elaborou onze perguntas, abrangendo gênero, região onde reside, idade, estado civil, declaração étnico-racial, escolaridade, se possui filhos, habitação, renda e o vínculo empregatício. Os dados serão expostos em gráficos, abrangendo a pesquisa nacional. Porém sempre que houver relevância, serão abordados dados por regiões específicas, pois em algumas questões os aspectos culturais e sociais regionais levaram a resultados muito diferentes e, como em todas as regiões há pelo menos 100 respondentes, é aceitável o cálculo de percentuais.

Frente ao dados obtidos com a compilação dos dados das 841 mulheres se identificou que as pesquisadas são mulheres jovens, com faixa etária inferior a 30 anos, perfazendo um percentual de $60,2 \%$, solteiras $(58,6 \%)$, brancas $(65,5 \%)$, sem filhos $(66,5 \%)$ e que moram com família $(78,2 \%)$. Um percentual elevado, de $77,7 \%$ das entrevistadas, estão ou já passaram pelo ensino superior. A maioria delas tem sua própria fonte de renda $(82,8 \%)$, e esta renda mensal é de até dois salários mínimos $(61,5 \%)$.

O estudo aponta que grande partes dessas mulheres possui ou desenvolve alguma atividade remunerada, deste modo representam grande parte da mão de obra em atividade no mercado de trabalho. Esta constatação vem ao encontro da observação de Heath (2013), que afirma que o número cada vez maior de mulheres no mercado de trabalho, tem influência em outros índices, como a redução dos casamentos prematuros e na gravidez precoce; por outro lado, aumenta o poder e a autoridade da mulher no lar. 
É interessante observar que, ao se traçar um paralelo entre as declarações das Gestoras entrevistadas e as mulheres pesquisadas, se constatam similaridades: nos dois grupos a maioria ingressou no mercado de trabalho próximo aos 20 anos de idade e, em ambos grupos, as integrantes buscaram o ensino superior. Sobre isso é importante trazer a observação de Coelho (2002) que afirma que as mulheres durante muito tempo estiveram submetidas aos homens através da restrição de diversos direitos, entre eles o acesso ao ensino superior. Este cenário se modificou, e no mundo contemporâneo, mais precisamente entre o os anos oitenta e final dos anos noventa, a participação da mulher no mercado de trabalho aumentou $35 \%$, principalmente em função de uma maior escolaridade, como destaca Pazello (2006).

Uma vez traçado o perfil das pesquisadas, no próximo item será discutida a percepção das mulheres pesquisadas sobre a discriminação de gênero, assédio, padrões de beleza e diferença salarial no ambiente de trabalho.

Correntemente, no decurso de suas carreiras, as mulheres sofrem com alguma hostilidade, prejulgamento e intolerância de alguns homens ou até mesmo das organizações nas quais estão inseridas De acordo com Ferreira (2012), as mulheres identificam a dessemelhança resultante de serem mulheres quando buscam postos no mercado de trabalho, em razão de que, por muitos anos, os cargos eram conquistados pelos homens, e as mulheres tinham mais espaço no mercado informal.

A percepção da diferenciação de gênero nas organizações pelas mulheres é evidente, o machismo nas empresas não costuma ser cortês com quem o desafia. Neste sentido o Gráfico 1 mostra que a grande maioria das pesquisadas, somando $55,4 \%$, sofreram elas próprias algum tipo de violência no exercício da profissão; frente a $44,6 \%$ das pesquisadas que afirmaram não ter passado por esta experiência. Entretanto, o Gráfico 2, mostra que $62,3 \%$ da pesquisadas vivenciaram ou vivem algum episódio referente a atos de violência ou discriminação contra a mulher no ambiente de trabalho. 
Gráfico 1 -Respostas das mulheres pesquisadas ao questão: Você já sofreu algum tipo violência no exercício da profissão?
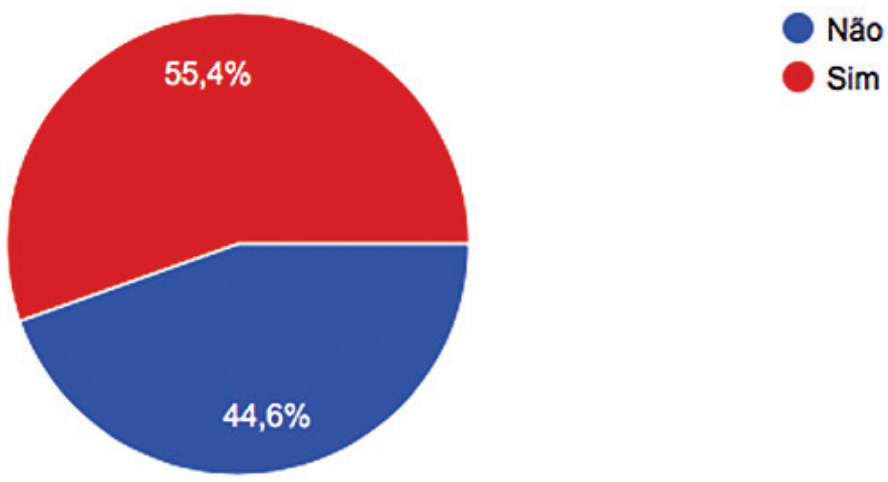

Fonte: dados da pesquisa, 2016

O Gráfico 2 complementa as informações obtidas com o Gráfico 1.

Gráfico 2 - Respostas das mulheres pesquisadas ao questionamento: Vive ou vivenciou algum episódio referente a atos de violência/ discriminação contra a mulher no ambiente de trabalho?

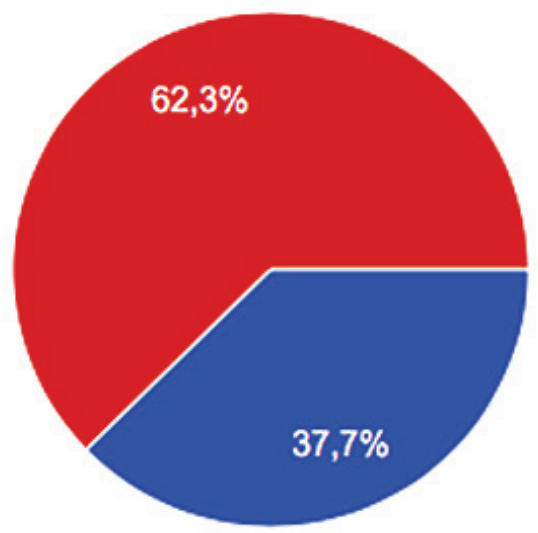

Não

Sim

Fonte: dados da pesquisa, 2016 
Ao constatar que a maioria das brasileiras foi vítima (55,4\%, GRÁFICO 1) ou percebeu atos de violência contra mulher (62,3\%, GRÁFICO 2) no ambiente laboral a questão óbvia foi solicitar as pesquisadas que identificassem o tipo de violência, onde os resultados obtidos estão apresentado no Gráfico 3.

Gráfico 3 - Respostas das mulheres pesquisadas a solicitação que identificassem os atos de violência sofridos ou observados no ambiente laboral

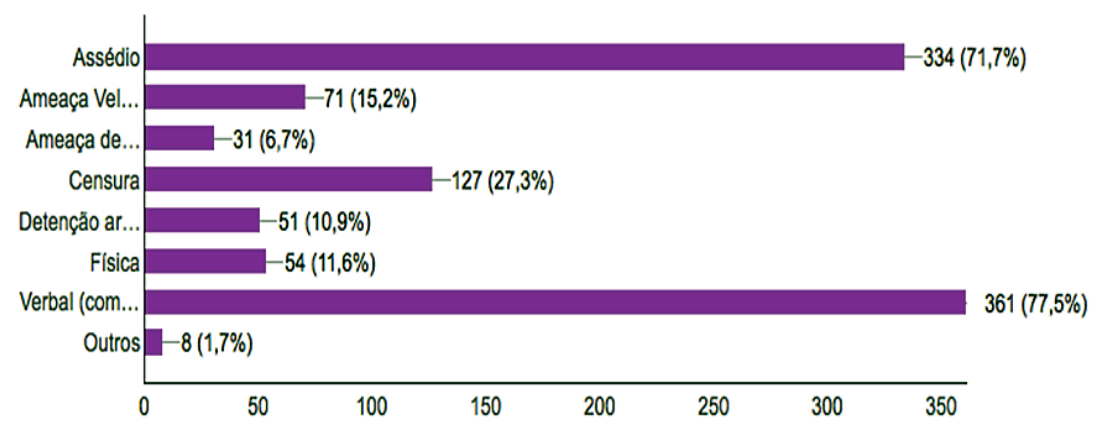

Fonte: dados da pesquisa, 2016

O Gráfico 3 mostra que $77,5 \%$ das pesquisadas foram vítimas de algum tipo de violência verbal, sendo citados um maior número de vezes os comentários desagradáveis ou desabonadores e preconceituosos; $71,7 \%$ das participantes da pesquisa já sofreram assédio; $27,3 \%$ foram vítimas de censura; $15,2 \%$, de ameaça velada; $11,6 \%$ das mulheres sofreu violência física; $10,9 \%$ foi vítima de detenção arbitrária; e 6,7\% das pesquisadas teve ameaça de morte.

Este cenário não difere do que foi observado com as Gestoras, pois elas também trouxeram relatos de intimidação masculina nas organizações. A Gestora A (2016) acredita que muitos homens não sabem lidar com a chefia feminina, pois eles se sentem inferiorizados. Ainda sobre o assédio e a 
intimidação, as três entrevistadas ressaltaram que sofreram intimidação por parte dos homens, seja ela direta ou velada, onde a Gestora A comentou:

[...] muitas vezes são comentários ou brincadeiras que no fundo têm uma "verdade" e acabam sendo desagradáveis e que, de uma certa forma, insultam veladamente a mulher. (GESTORA A, 2016).

Mais adiante a Gestora A trouxe uma experiência pessoal neste contexto

Eu já passei por uma intimidação masculina quando trabalhava num hospital na qual era assistente do administrador e um médico me perguntou porque que eu era assistente, e fez uma pergunta bem pejorativa, que só faltou dizer que eu dormia com o diretor, por isso que eu ocupava o cargo de assistente, tentei fazer que não tinha entendido a pergunta e disse que eu era assistente porque sou competente, mas foi uma situação muito chata e sinceramente ridícula (GESTORA A, 2016).

A Gestora B ao ser questionada se já foi intimidada por algum homem no ambiente de trabalho, se referiu a uma instituição onde trabalhou, na qual foi intimidada pelo chefe imediato, que fez uma proposta de trabalho, em que ela assumiria um determinado cargo, que teria mais horas de trabalho, porém o chefe vinculava essa proposta com uma confabulação de que ela era bonita, perguntando se já tinha trabalhado de modelo, ao que a Gestora B sentiu-se intimidada e sabia que era um diálogo com segundas intenções. A Gestora B afirmou que:

Já sofri assédio, mais de uma vez, assédio sexual mesmo como convite para sair, e bobagenzinhas nas entrelinhas(GESTORA B).

Na sequencia, se investigou a existência de pressão ou necessidade da realização de alguma intervenção de beleza solicitada pela organização para que a pesquisada se enqua- 
drasse nos padrões estabelecidos pela empresa. Os resultados, mostraram que 55,5\% das mulheres pesquisadas já fizeram alguma intervenção para se enquadrar na empresa, nas seguintes modalidades: $32,2 \%$ modificou a vestimenta; $11,7 \%$ fez alguma intervenção estética, sendo citadas escova progressiva, para alisar os cabelos; pintura ou modificação do corte dos cabelos; $9,2 \%$ relatou modificações com relação ao corpo, sendo a dieta a ação com maior percentual; $1 \%$ das pesquisadas apontou as intervenções cirúrgicas com finalidade estética. Entretanto $44,5 \%$ disseram não ter feito nenhuma intervenção de beleza para se integrar na empresa.

Gráfico 4 - Respostas das mulheres pesquisadas ao questionamento: Já fez alguma intervenção de beleza para se enquadrar em padrões estabelecidos pela organização?
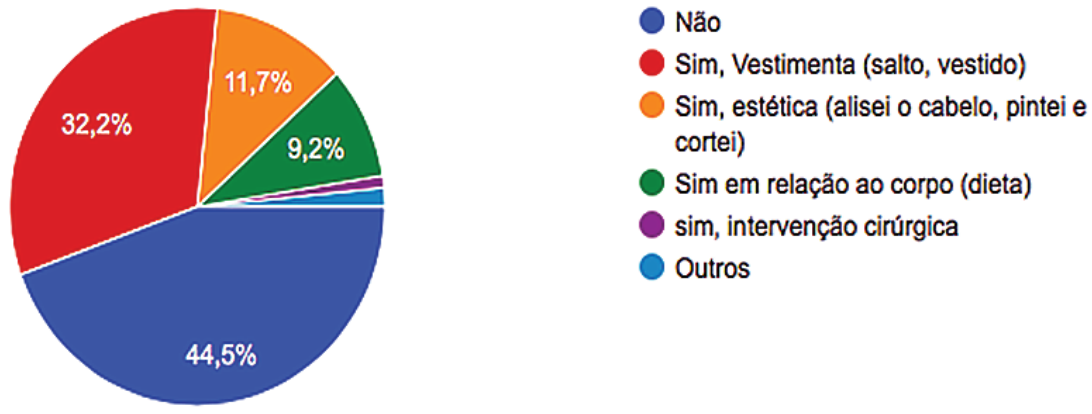

Fonte: dados da pesquisa, 2016

O exposto no Gráfico 4 está em consonância com a observação de Bohn (2004), que afirma que o protótipo da mulher perfeita nos dias atuais é exibido diversamente e incansavelmente pela mídia, seja ela por revistas, indústria da moda, passarelas e televisão, propondo juventude eterna. Adicionalmente as próprias mulheres estão em busca de medidas e padrões ilusórios, buscando a perfeição e a juventude para se 
enquadrar em padrões irreais impostos pela sociedade, como destaca Greer (2001).

Se pode constatar que estas ações partiram das próprias mulheres pesquisadas, desejosas de se enquadrarem nos padrões da sociedade ou até mesmo da organização, no entanto o estudo demonstra que $57,4 \%$ das pesquisadas já sofreram preconceito, pela sua aparência ou pelo seu modo de vestir.

O próximo tema traz as diferenças salariais entre os gêneros, ao que se propôs a seguinte assertiva: Há diferença salarial se considerado o gênero do colaborador, com os resultados apresentados no Gráfico 5.

Gráfico 5 - Respostas das mulheres pesquisadas a assertiva: Há diferença salarial se considerado o gênero do colaborador

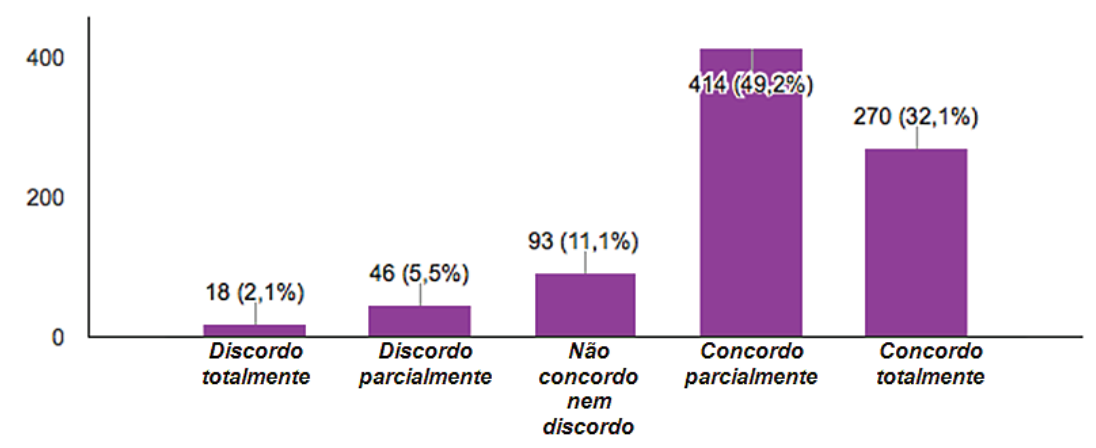

Fonte: dados da pesquisa, 2016

Frente a esta assertiva, $81,3 \%$ das pesquisadas concordam ou concordam plenamente que de fato há diferenciação salarial entre os gêneros; $11,1 \%$ mantém a neutralidade; e apenas $7,6 \%$ discordam ou discordam completamente que haja essa discriminação (GRÁFICO 5).

Esta não é apenas a percepção das pesquisadas, pois por mais que as conquistas das mulheres dos últimos anos tenham avançado, ainda há desvantagens em relação ao homem no

ReMas - Revista Metodista de Administração do Sul, v. 2, N. 1, 2017 
mercado de trabalho. Conforme a revista Ensino Superior (2016), a partir de dados do Fórum Econômico Mundial, a desigualdade de gênero no Brasil aumentou, pois no ano de 2014 o país ocupava o $71^{\circ}$ lugar no ranking da igualdade salarial entre homens e mulheres, e hoje ocupa a $85^{\circ}$ posição, tendo em dois anos subido 14 posições rumo as diferenças salariais entre as mulheres e os homens.

A maternidade nas organizações é sem dúvida uma temática importante, pois normalmente a maternidade é temida pelas empresas e é fonte de incertezas profissionais para as mulheres. Neste contexto, algumas organizações ainda adotam a política de não contratar mulheres que potencialmente possam gestar ou que declarem desejar filhos. A questão da compatibilização da maternidade com o trabalho ainda gera muita desigualdade de gênero, pois mesmo que a gestante tenha leis que a defendam e que impeçam seu desligamento, isto não interrompe as discriminações de algum gestores e colegas no ambiente laboral.

O estudo mostra que $12,6 \%$ das pesquisadas estão grávidas, e trouxe que $33,5 \%$ das pesquisadas possuem filhos.

Em um primeiro momento, o percentual de $12,6 \%$ de gestantes parece baixo, entretanto há que se destacar que o grupo pesquisado é bastante jovem, $46,6 \%$ das pesquisadas têm o superior incompleto, portanto podem ainda estão fazendo a sua formação e 14,2\% é estagiária, sendo notório o fato das mulheres adiarem a maternidade, inclusive por questões profissionais, como destaca Pazello (2006), cada vez mais as mulheres optam por ter filhos mais tarde por darem ênfase primeiro na carreira profissional, após sua ascensão no mercado de trabalho.

O passo seguinte, foi verificar a opinião das mulheres sobre se existe algum tipo de intimidação por parte dos gestores frente a possibilidade da funcionária engravidar. A pesquisa 
mostrou que $84,6 \%$ das mulheres pesquisada estão de acordo ou totalmente de acordo que há intimidação por parte de alguns gestores frente a possibilidade da gravidez; só 5,1\% das pesquisadas discorda em algum grau desta assertiva.

Foram abordam questões sobre o tema e alcançaram resultados semelhantes. Foi abordado se há possibilidade de gravidez pode ser um fator de eliminação ou restrição ao acesso de um alto cargo; A gravidez é um fator que pode gerar discriminação no mercado de trabalho; A comunicação da gravidez pode acarretar algum tipo de discriminação no ambiente de trabalho.

Os resultados são evidentes, mais de $70 \%$ das pesquisadas, frente a estas assertivas, concorda, parcial a totalmente que, de alguma forma, a maternidade traz desvantagens na vida profissional, representada por algum processo negativo, como discriminação, restrição ao crescimento dentro da organização ou algum tipo de discriminação.

As Gestoras foram unânimes, quando questionadas sobre a maternidade se fator de discriminação, afirmando que muitas empresas encaram a possibilidade de uma funcionária engravidar como um prejuízo, pois o período afastamento é muito longo, e muitas mulheres para ter mais tempo com seus bebes juntando as férias e a licença maternidade. Sobre o tema a Gestora A, afirmou que:

Em vários casos, há várias empresas que os gestores não contratam as mulheres por saber que elas estão em período fértil, e por conta disso, podem querer ter filhos, então dependendo da empresa, há sim discriminação. (GESTORA A, 2016).

Gestora B manifestou que:

Tenho certeza que há, [...] as vezes preferem uma que já tenha filhos, pois não vão se ausentar no período da gravidez, eu já presenciei

Remas - Revista Metodista de Administração do Sul, v. 2, N. 1, 2017 
porque trabalhei muito tempo com direito empresarial, assessorando empresas, e há vários gestores que querem contratar mulher solteira, como se mulher solteira não pudesse dar a luz a um bebê, ou então mulheres que já estão em idade mais avançada, ou que já têm filhos, deste modo futuramente não teriam filhos e não iriam se afastar do trabalho, em razão da licença gestante. (GESTORA B, 2016).

A Gestora C corroborou as observações, afirmando que:

Em minha loja não são contatadas mulheres, pois ainda é meu pai que é o dono e que é responsável pela contratação, e ele não contrata mulher, porque elas têm a possibilidade de engravida e ficam por muito tempo ausentes, infelizmente é assim. Ele não contrata mulher! (GESTORA C, 2016).

Lamentavelmente, a gravidez ainda é um problema para algumas organizações e um assunto delicado, se percebeu durante a conversa com as Gestoras, todas mães, que elas sentem a falta de consideração e respeito de alguns colegas e gestores com este momento importante do mundo feminino e até mesmo masculino, que as empresas parecem não valorizar.

Nas cinco regiões as respostas foram semelhantes, ou seja sobre a discriminação com relação a gravidez não incidem fatores culturais e regionais, pois não se observou variação nos resultados.

Diversas lutas e revoluções femininas aconteceram no decorrer dos séculos, e, para a maioria das mulheres, o combate à discriminação e a opressão ainda é diário. Muitas mulheres não são mais submissas ao homem e cada vez mais conquistam espaços, ficando independentes pessoal e financeiramente, derrubando as barreiras machistas que as cercearam durante toda a história. Hoje ocupam cargos ditos masculinos, há alguns anos atrás ninguém imaginava uma mulher presidente, governadora, gestora de empresas, entre diversas outras profissões. 
Na continuidade, a pesquisa buscou verificar se as participantes conhecem alguma mulher que possui cargo profissional de destaque, ao que $83,7 \%$ das pesquisadas respondeu positivamente.

A progressão da mulher no mercado de trabalho, não ausentou a mulher de tarefas domésticas, assim as mulheres trabalham mais horas que os homens, configurando a dupla jornada de trabalho. Segundo o IPEA (2011), as mulheres que trabalham fora de casa têm uma grande sobrecarga em horas semanais dedicadas aos afazeres domésticos, de cerca de 25 horas semanais, frente a dez horas de trabalho doméstico semanal dos homens.

Se constata assim que, apesar da evolução da mulher dentro de atividades que já foram exclusivamente masculinas, conquistando espaço com instrução e dedicação, lutando constantemente contra a discriminação e até mesmo contra a violência representada pelas situações de assédio no ambiente laboral, os salários pagos às mulheres não acompanharam este crescimento. Entretanto e apesar disto as mulheres têm alcançado postos e conquistado respeito nas diversas esferas onde atuam, mostrando dedicação e profissionalismo e uma forma feminina de gerir as organizações.

\section{CONSIDERAÇÕES FINAIS}

O estudo contatou que a maioria das pesquisadas são mulheres jovens, com faixa etária inferior a 30 anos, perfazendo um percentual de $60,2 \%$, em geral solteiras $(58,6 \%)$, brancas $(65,5 \%)$, sem filhos $(66,5 \%)$ e que moram com família $(78,2 \%)$. Um percentual elevado, de 77,7\% das entrevistadas, estão ou já passaram pelo ensino superior. A maioria delas tem sua própria fonte de renda $(82,8 \%)$, e esta renda mensal é de até dois salários mínimos (61,5\%). Ainda se observou que a maioria dessas mulheres possui ou desenvolve alguma atividade

ReMAS - Revista Metodista de Administração do Sul, v. 2, N. 1, 2017 
remunerada. Com relação as Gestoras, a faixa etária está ao redor dos 40 anos e todas têm filhos. É interessante observar que, ao se traçar um paralelo entre as declarações das Gestoras entrevistadas e as mulheres pesquisadas, há similaridades: nos dois grupos a maioria ingressou no mercado de trabalho próximo aos 20 anos de idade e, em ambos grupos, as integrantes buscaram o ensino superior.

Pode detectar a percepção das mulheres brasileiras e Gestoras sobre a discriminação de gênero, assédio, padrões de beleza e diferença salarial no ambiente de trabalho. Tanto as pesquisadas, como as entrevistadas, têm a mesma percepção: a discriminação existe e se expressa das mais diversas formas, desde uma remuneração desigual entre os gêneros pela mesma atividade; através do assédio, pela violência com que são tratadas nas organizações, se destacando a violência verbal, citada por mais de $77 \%$ das pesquisadas. Aqui cabe salientar que $83 \%$ das mulheres pesquisadas da Região Centro-Oeste foram vítimas de violência no trabalho; frente a 39,1\% vítimas de violência na Região Sul.

O estudo mostrou que maternidade influencia na disputa por vagas ou cargos no ambiente de trabalho se observou que, em um universo de mulheres onde 33,5\% têm filhos e 12,6\% está grávida, existe a certeza de que a maternidade pode ser fator de eliminação ou restrição a cargos ou gera discriminação. Este resultado foi integralmente corroborado pelas Gestoras, onde uma delas afirmou que na empresa onde trabalha não são contratadas mulheres em pelo medo de uma gestão, que afastaria a funcionária, onerando a empresa. Assim, se percebeu que as mulheres sentem que a maternidade é um dos grandes obstáculos, um dos fatores que as afasta das oportunidades.

O estudo conclui que as mulheres que compõe o universo da pesquisa, tanto qualitativa, quanto quantitativa, entendem não há igualdade de gênero nas oportunidades no mercado de 
trabalho, sendo que as mulheres encontram-se em desvantagem frente aos seus colegas homens. Apesar disto, acreditam que não existem profissões exclusivamente femininas, nem cargos que devam ser ocupados por um único gênero, que as mulheres são mais abundantes que os homens no trabalho informal e todas conhecem mulheres em cargo de destaque nas organizações. Infelizmente um percentual elevado entre as pesquisadas conhece mulheres que não se sentem realizadas profissionalmente e que se sentem inferiores ao homens no trabalho.

Também se constatou que o universo de mulheres da pesquisa sentem que há uma grande diferença entre o tratamento dispensado aos dois gêneros no mundo do trabalho, mesmo que na sociedade contemporânea as mulheres componham uma parcela significativa da força de trabalho nas organizações, os diversos direitos assegurados por lei, não impedem a discriminação de gênero.

$\mathrm{Na}$ opinião do autor, as diferenças de gênero vêm diminuindo, porém sem dúvida uma distinção entre os sexos e isso tem que ser combatido.

\section{REFERÊNCIAS}

BASSANEZI, Carla . Mulheres dos anos dourados. In.: PRIORI, Mary Del. Historia das mulheres no Brasil. 7 ed. São Paulo: Contexto, 2004. p.607 - 639 .

BEAUVOIR, Simone de. O segundo sexo: Fatos e mitos. 4. ed.São Paulo: Difusão Européia do Livro, 1970. 309 p.

BELLO, José Luiz de Paiva. Educação da mulher: a perpetuação da injustiça. Rio de Janeiro: Clube de Autores , 2012.

BESAMUSCA, Janna; TIJDENS, Kea; KEUNE, Maarten; STEINMETZ, Stephanie. Working Women Worldwide. Age Effects in Female Labor Force Participation in 117 Countries.WorldDevelopment, v. 74, p. 123-141, 2015. Disponível em: http://www.sciencedirect.com/science/ article/pii/S0305750X15000996>. Acesso em: 14 abr. 2016. 
COELHO, Nariana; MUZART, Zahidé Lupinacci (Orgs.). Evolução do feminismo: subsídios para a sua história. 2 ed. Curitiba: Imprensa Oficial do Paraná , 2002.

CRESWELL, John W. Projeto de pesquisa: Métodos qualitativos, quantitativos e misto. 3. ed Porto Alegre: Artmed, 2010. 296 p.

FERREIRA, Maria da Luz. As desigualdades de rendimentos por gênero na RMBH e no município de Montes Claros. In.: SOUZA, Márcio Ferreira (ORG.). Desigualdade de gênero no Brasil: novas ideias e práticas antigas. Belo Horizonte: Fino Traço, 2010. p. 151 - 170.

FONSECA, Cláudia. Ser mulher, mão e pobre. In.: PRIORI, Mary Del. Historia das mulheres no Brasil. 7 ed. São Paulo: Contexto, 2004. p.511 - 553.

GIL, Antonio Carlos. Como elaborar Projetos de pesquisa. 4. ed. São Paulo: Atlas, 2002.

GREER, Germaine. A mulher inteira.Tradução Alda, Rio de Janeiro: Record, 2001.

HEATH, Rachel. Women's Access to Labor Market Opportunities, Control of Household Resources, and Domestic Violence: Evidence From Bangladesh. World Development, v. 57, p. 32-46, 2014. Disponívelem: <http://www.sciencedirect.com/science/article/pii/ S0305750X13002404>. Acesso em: 13 abr. 2016.

IPEA, Instituto de Pesquisa Econômica Aplicada. Retrato da desigualdade de gênero e raça.4. ed. Brasília: IPEA, 2011.

KLEIN, Amarolínda Zanela; SILVA, Lisiane Vasconcellos da; MACHADO, Lisiane; AZEVEDO, Debora. Metodologia de pesquisa em administração: uma abordagem prática. São Paulo: Atlas, 2015.

LOPES, Maria Sbalqueiro. Direito do Trabalho da Mulher: Da proteção à promoção. Disponível em :<http://www.scielo.br/scielo. php?script=sci_arttext\&pid=S0104-83332006000100016 $>$ Acesso em 30 out. 2015.

MADALOZZO, Regina; MARTINS, Sergio Ricardo; SHIRATORI, Ludmila, Participação no mercado de trabalho e no trabalho doméstico: homens e mulheres têm condições iguais?. Disponível em $:<$ http://www.scielo.br/scielo.php?script=sci_arttext\&pid=S0104-026X2 010000200015\&lang=pt>Acesso em 28 out. 2015. 
MARCONI, Marina de Andrade; LAKATOS, Eva Maria. Fundamentos de metodologia científica. 7. ed. São Paulo: Atlas, 2010.

MERIC, Ismail; ER, Mustafa; GORUN, Mustafa.Managing Diversity in education: USAFA Case. Procedia Social and Behavioral Sciences, v. 195, p. 72-81, 2015. Disponível em: <http://www.sciencedirect.com/ science/article/pii/S1877042815038100 >. Acesso em: 12 abr. 2016.

NEVES, Márcia. A violência conta a mulher no mercado de trabalho. Rio de Janeiro: E-papers, 2009. 138p.

NG, Eddy S. W.; WYRICK, Cheryl R. Motivational bases for managing diversity: A model of leadership commitment. Human Resource Management Review, v. 21, p. 368-376, 2011.Disponívelem: <http:// ac.els-cdn.com/S1053482211000325/1-s2.0-S1053482211000325-main. pdf?_tid=c48e3e20-f855-11e5-881a-00000aab0f6c\&acdnat=1459548475_ bf7f70d7898d90d0df26c6d735118602>. Acesso em: 01 abr. 2016.

PAZELLO, Elaine Toldo. A maternidade afeta o engajamento da mulher no mercado de trabalho?:um estudo utilizando o nascimento de gêmeos como um experimento natural. Disponível em $:<$ http://www.scielo.br/scielo.php?script=sci_arttext\&pid=S0101-41612006000300004\&lang=pt\#nt01>Acesso em 01 nov. 2015.

ENSINO Superior, Sãp Paulo, v. 18, n. 205, dez.2015/jan.2016. Disponível em: http://www.semesp.org.br/site/publicacoes/revista-ensino-superior/revista-ensino-superior-dezembro-de-2015/. Acesso em: 10 nov. 2016.

SALAHODJAEV, Raufhon; AZAM, Sardor. Intelligence and gender (in)equality: Empirical evidence from developing coutries. Intelligence, v. 52, p. 97-103, 2015. Disponível em: < http://www.sciencedirect. com/science/article/pii/S0160289615001026>. Acesso em: 19 mai. 2016.

STEARNS, Peter N. História das Relações de gênero. 2 ed. São Paulo: Contexto, 2010.

THOMAS, D. A., ELY, Robin. Making Differences Matter: A new Paradigm For Managing. Harvard Business Review 74, no. 5 (September-October 1996): 79-90. Disponívelem: <http://www.hbs.edu/ faculty/Pages/item.aspx?num=5722>. Acesso em 28 abr 2016.

VIANNA; Segadas; SÜSSEKIND, Arnaldo; MARANHÃO, Délio. Instituições de direito do trabalho. 14. ed. Volume II. São Paulo:LTDA, 1993. 1349 p. 